Epenthesis and Elision in Rosé's Instagram @roses_are_rosie

\title{
Adib Rifqi Setiawan
}

Rosénator Warrior

rosenatorwarrior@gmail.com

\section{Abstract}

The present paper seeks to analyze Rosé's caption on her instagram @roses_are_rosie based on linguistics's concept named epenthesis and elision.

Keywords: elision, epenthesis, instagram, linguistics, Rosé 